\title{
Mobility, Media, and Data Politics
}

William L Allen (University of Oxford)

This manuscript is a pre-print version of a forthcoming chapter in an edited volume.

Suggested citation: Allen, William (2019). 'Mobility, Media, and Data Politics', in K. Smets,

K. Leurs, M. Georgiou, S. Witteborn, and R. Gajjala (eds), Handbook of Media and

Migration, London: SAGE, pp.180-91.

\section{Abstract:}

Researchers increasingly seek to apply, expand, and improve large-scale data collection and analysis processes, sometimes called 'Big Data' approaches. Given this shift, there is a growing need for reflection on these developments to make sense of them in meaningful and ethical ways. In this chapter, I argue that the concept of 'data politics', coming from the field of critical data studies, offers useful guidance for media and mobility studies. Specifically, it moves debate towards identifying for whom, under what circumstances, and to what ends are data of all types and sizes created, collected, and used. Addressing these kinds of questions requires acknowledging the assumptions and politics inherent to claims about what 'effective' data practices look like, as well as how migrants and mobility are enacted and represented through data. To illustrate these points, I highlight how data politics intersect with the study of mobility in two areas related to media: measuring mobility through data categorization and collection, and communicating media research findings through data visualization. I conclude by outlining aspects of a critical data politics agenda as they apply to media and migration studies. 
Keywords: Big Data, categorization, critical data studies, data politics, media, migration, visualization

Biography: William L Allen is a Fellow in Political and Development Studies at Magdalen College, University of Oxford, and a Researcher at the Centre on Migration, Policy, and Society (COMPAS). His research areas are in political communication and public opinion, particularly how media relate to immigration attitudes and policymaking. Currently, he is focusing on data visualizations about migration and mobility as visually brokered outputs that relate to public perceptions and political behavior. He is also developing theories of knowledge exchange among migration researchers and the wider public, in order to inform more effective practice. Recent publications on these subjects have appeared in journals including The International Journal of Press/Politics, International Migration Review, and Public Understanding of Science. Notably, his research investigating how British civil society groups use data and evidence won the inaugural 2016 Carol Weiss Prize for the best early-career paper recently published in the journal Evidence \& Policy. 
On September 19, 2016, the United Nations General Assembly adopted the New York Declaration for Refugees and Migrants. Among other commitments, it emphasized 'the importance of improved data collection, particularly by national authorities, and will enhance international cooperation to this end' (United Nations General Assembly, 2016, p. 8). Such data would intend to shed light on regular and irregular international migration, economic impacts, levels of human trafficking, and the needs of both people who are moving as well as host communities. This document set the stage for two global compacts on refugees and migrants respectively, with a goal of producing specific recommendations for member states.

After the New York Declaration, several bodies including the International Organization for Migration (IOM) published briefings and statements on key themes to inform preparations for the global compacts. One of these themes dealt with the issue of statistical data collection. A preparatory IOM briefing titled 'International Migration Statistics' raised five key challenges: (1) taking stock of what data about migration are already collected and available; (2) improving states' capacities for collecting and analysing data; (3) coordinating among states to identify common gaps and shared priorities; (4) exploiting emerging and non-traditional sources of data including 'Big Data'; and building mechanisms for systematically monitoring progress on all of these areas (International Organization for Migration, n.d., pp. 3-4). In this context, 'Big Data' holistically refers to 'things one can do at a large scale that cannot be done at a smaller one, to extract new insights or create new forms of value, in ways that change markets, organizations, the relationship between citizens and governments' (Mayer-Schönberger \& Cukier, 2013, p. 6).

These developments illustrate how data and statistics, as well as the wealth of research and evidence based on them, are increasingly central to the outputs, institutions, practices, and assumptions of global migration policymaking (Boswell, 2009; Boswell, Yearley, Fleming, Rodrigues, \& Spinardi, 2015). For example, a recent report by the IOM's 
Global Migration Data Analysis Centre (GMDAC) sets out its case for better global migration data collection, analysis, and communication:

...[S]ound data and analysis can enable decision makers to identify a problem, design a policy response, as well as implement and evaluate relevant interventions. Effective use of data can help transform the migration debate, which is often driven by emotion and political sensitivities, into one rooted in evidence and objective analysis - and thus enable better outcomes for migrants, governments and societies alike. (Global Migration Data Analysis Centre, 2018, p. 22)

Earlier, some argued that 'Big Data might help to improve our understanding of migration trends around the world', and will necessarily involve 'developing new approaches, new partners and new sources and uses of data' (Laczko \& Rango, 2014, p. 20). These new sources could include social media data, mobile phone records, or national administrative data regarding residents' access to public services (Rango \& Vespe, 2017). More data that are disaggregated along key dimensions potentially confer several benefits — not least of all a more comprehensive picture of actual migration trends and impacts that can, in turn, inform decision-makers at local, national, and international scales.

But others have expressed skepticism towards these claims, particularly of the extent to which they could be realized in practice, and who would really benefit from an expanding data-centered agenda: 'there is a real risk that data management becomes an end in itself...outstripping the ability of aid agencies to analyze the information they have collected and to use it in effective ways' (Crisp, 2018). Pursuing more and better data for their own sakes may have a counterproductive impact, delaying lasting and meaningful improvements to migrants' and refugees' lives by drawing attention and resources away from other activities that might have more immediate or directly-felt impacts. Moreover, as noted in the original New York Declaration and IOM's own thematic briefings, using data generated 
through social media or mobile technologies raises serious ethical issues of privacy and ownership — never mind questions about the veracity of the data themselves.

Fundamentally, the challenge is that 'decision makers need to be convinced of the value that migration data can deliver' (Global Migration Data Analysis Centre, 2018, p. 15), in whichever forms those data may take. Yet, there is no clear consensus on what that value actually is, or how it might be transformed into responsible action. Given these different perspectives, how can migration researchers, policymakers, and practitioners make sense of the challenges, opportunities, limitations, and benefits of data? In this chapter, I argue that the concept of 'data politics' (Ruppert, Isin, \& Bigo, 2017) as it has been developing in fields such as critical data studies and science and technology studies (STS) provides a useful guide for addressing this question. Notably, it directs attention away from what Kate Crawford and her colleagues have called 'the tired binary of big data —is it good or bad?' (2014, p. 1665), and towards more realistic, yet critical, questions about how, for whom, under what circumstances, and to what ends are data created, collected, and used.

My argument unfolds in three parts. First, I outline what data politics are, and how they feature in data worlds, subjects, and rights. Second, I apply this concept to the study of media and mobility, specifically focusing on two areas: measuring mobility by categorizing and collecting data about individuals and populations; and communicating research findings to decision-makers and members of the public through visual representations of these data. In this section, I use examples from my own and others' research, which are largely drawn from European cases and experiences. I have also intentionally used the term 'mobility' alongside 'migration' as a way to signal how my discussion of data politics applies to all kinds of human movement — not just those people, paths, or places that are given priority through the label of 'migration' or 'migrant' (Allen et al., 2018). Third, in an exploratory way, I outline the implications of interactions among data politics and migration politics, drawing out some 
lessons for future research, policy, and practice. Situating my contribution against the backdrop of growing policy interest in data and migration, I aim to link and synthesize several developing literatures to provide a guide for scholars and practitioners concerned with navigating the promises and pitfalls associated with data and their usage in the fields of media and mobility studies.

\section{Data Politics and the Contributions of Critical Data Studies}

In their commentary setting out the concept of, and an agenda for studying data politics, Evelyn Ruppert and her colleagues observe how data 'has potential force that can be realized in myriad ways through its uptake and deployments' (2017, p. 2). These contribute to three key aspects of data and society: the material objects, landscapes, and infrastructures associated with data and their transmission (what they call 'worlds'); the ways that data collection, filtering, and usage create new kinds of individuals that relate to one another in new ways ('subjects'); and how and to what extent subjects claim and struggle over ownership of their data ('rights'). The concepts of worlds, subjects, and rights express how data relate to politics in how they are constructed, perceived, and used, as well as create new kinds of politics through contestation: 'data politics is concerned with not only political struggles around data collection and its deployments, but how data is generative of new forms of power relations and politics at different and interconnected scales' (Ruppert et al., 2017, p. 2).

Of course, that data and their associated tools and logics exert power-often via governments with sometimes unintended if not disastrous consequences - is not a new idea (Eberstadt, 1995). What are new, however, are the datafied media and channels through which power flows, and the implications these have for politics, society, and economies (boyd \& Crawford, 2012). The field of critical data studies, as an enterprise concerned with 
questioning data of all types and the assumptions made about them (Dalton, Taylor, \& Thatcher, 2016; Iliadis \& Russo, 2016), aims to theoretically and empirically map these flows.

What does an appreciation of data politics, rooted in critical data studies, offer to studies of media and mobility? First, it provides concrete questions that can guide research beyond simplistic binaries of data and their accompanying media being 'good or bad'. How, for instance, are data collected in specific migratory contexts, and who is given or denied access in this process? What factors at individual, organizational, or institutional levels impact the creation and implementation of data-handling norms or policies - and how are these enacted and challenged in practice? Whose agendas are represented in the ways that data are used and justified in public as well as private settings: those of migrants, states, private corporations, intergovernmental organizations, others?

Second, addressing these kinds of questions is more useful for debating what constitutes 'effective' data collection, curation, use, and communication. Assertions about the promises and risks of data for media and mobility research hinge on certain understandings of what 'effectiveness' looks like and how it could be measured. Is an effective data strategy one that prioritizes comprehensiveness and parsimony across diverse media sources? Or is it one that, as far as possible, retains qualitative nuance and contextual information that aids interpretation? Such understandings are neither universally held, nor should researchers expect them to be (Kennedy, Hill, Aiello, \& Allen, 2016). Instead, as illustrated by critical realist approaches to social science, the 'critical' element asks 'what works for whom in what circumstances and in what respects' while 'learn[ing] from (rather than control[ling] for) real-world phenomena such as diversity, change, idiosyncrasy, adaptation, crosscontamination and programme failure' (Pawson, Greenhalgh, Harvey, \& Walshe, 2005, p. $32)$. 
Whether they explicitly invoke elements of this approach or not, critical scholars of data offer a great deal to the study of media and mobility as they investigate themes that are deeply intertwined with forms and practices of (im)mobility. For example, these might include how data and algorithms are implicated in discriminatory practices (Leurs \& Shepherd, 2017), or how refugees' experiences and decisions are increasingly shaped by digital as well as physical infrastructures (Dekker, Engbersen, Klaver, \& Vonk, 2018; Latonero \& Kift, 2018). Moreover, the growth of open-access journals such as Big Data \& Society and international conference series including Data Power that directly engage with data politics illustrates how the intellectual landscape has changed to accommodate a wider range of questions. These kinds of changes are heartening. In the following section, I focus on two areas in which data politics intersect with media and mobility, some of which draw on my own experiences of doing research in political communication.

\section{How Data Politics, Media, and Mobility Intersect}

\section{Measuring mobility: Collecting and categorizing data}

Lisa Gitelman and Virginia Jackson provide a perennially useful reminder of how the phrase “"raw data" is an oxymoron' that 'often leads to an unnoticed assumption that data are transparent, that information is self-evident, the fundamental stuff of truth itself' (2013, p. 2). This is most apparent in the ways that data about migrants - their reasons for moving, as well as through which legal channels they enter a country—are collected, organized, and categorized. After all, answering the question 'who counts as a migrant' is fundamental not only for scholarly research but also for identifying the scale and scope for policy and practical interventions (Anderson \& Blinder, 2017).

From a political point of view, it comes as no surprise that states have an interest in identifying and counting migrants: "much of "what government does" consists of obtaining 
information' (Hood \& Margetts, 2007, p. 21). Even the term 'statistics' originates from German to mean 'state numbers' (Ball, 2015), or information about a population collected and held by the state. A primary way that governments collect data about residents is through censuses, usually implemented at regular intervals. This tool—a seemingly routine, bureaucratic method of documenting and organizing demographic information — is actually an important means by which populations, including migrants, are both carved out and made legible (Scott, 1998) as well as obscured or hidden (Allen et al., 2018).

In her comparative and historical work on censuses, Evelyn Ruppert argues that these tools are 'a subjectifying technology through which individuals examine and articulate who they are in relation to others in the population... and through recognised census categories groups can claim or be denied social and political rights' (2007, pp. 14-15). Indeed, she observes, 'population knowledge is indispensable to governing and the allocation of rights' (Ruppert, 2011, p. 229). Therefore, data politics as applied to the tasks of identifying and categorizing migrants raises critical questions about how values are generated and applied to people. These values, in turn, have real-world effects through the various policies that invoke them. For example, Madeleine Sumption considers how imposing a simplifying set of assumptions about reasons for migration...could facilitate a tendency to create hierarchies of 'good' and 'bad' migrants based purely on available metrics of economic contribution, to the detriment of noneconomic considerations that are less easily measurable. (Allen et al., 2018, p. 227)

Besides being enacted through tools like censuses that involve requests on the part of enumerators or surveyors, data politics also arise through processes of reusing masses of already-collected information about people who are, or have been, on the move. An emerging example of this kind of data would be records of mobile phone usage (Blumenstock, 2012). On the one hand, this kind of data collection offers potential for new kinds of interventions. Take initiatives like the Turkish 'Data for Refugees' competition, which makes anonymized 
call detail record (CRD) data from Türk Telekom available to researchers in an effort to improve the living conditions of Syrian refugees in Turkey (Data for Refugees Turkey, 2018). It illustrates the ambition with which private corporations and researchers with data analysis skills are directing their attention to pressing needs of refugees and migrants. These kinds of partnerships, relying on data that are very specific and detailed, arguably produce more responsive and targeted outcomes than those based on census snapshots that are five or ten years apart.

On the other hand, such developments come with methodological and ethical risks. These are clearly illustrated by Linnet Taylor's (2016) work that examines the challenges associated with measuring human mobility in low- to middle-income countries using phone data. She analyzed the case of the 'Data for Development (D4D)' challenge launched by the company Orange in 2012-13, which made available to researchers a year's worth of anonymized records from subscribers in Côte d'Ivoire. These records included details of calls, SMS exchanges, and the spatial trajectories of subsets of users at different levels of resolution.

Methodologically, the partial and sometimes haphazard nature of individuals' mobile data means identifying who is actually migrating is prone to numerical inaccuracies. Especially in developing country contexts, 'a lack of coverage can result in people having multiple SIM cards from different providers to get the best chance of a signal. Equally, one SIM card can have multiple users' (Taylor, 2016, p. 327). Locational inaccuracy based on insufficient phone usage is another problem. This is relevant in conditions of forced movement when people might have fewer opportunities or resources to buy credit or recharge their mobiles, and thereby generate geo-located data in the first place (Bengtsson, Lu, Thorson, Garfield, \& Von Schreeb, 2011; Taylor, 2016). 
As a result, trying to measure mobility using these techniques encounters significant difficulties: 'the data may be non-specific in ways the researcher does not understand due to cultural or geographic distance, and the necessary qualitative information is not easily accessible to researchers who are not social scientists' (Taylor, 2016, p. 327). Tellingly, she reports that out of 150 teams that participated in the D4D challenge that year, only one was based in Africa (in Cameroon) and only one other researcher had visited Côte d'Ivoire as part of the competition to understand the limitations of the dataset from the perspectives of users.

In addition to issues of accuracy, these data collection practices also raise ethical concerns. One of the most well-rehearsed, though by no means less important, involves protecting the privacy of data subjects. For Taylor (2016, p. 329), 'conducting ethical research involves the effort not to see too clearly', while acknowledging how mobile phone data 'may also constitute a way for those in need of visibility to become visible... and better protected from danger, deprivation or exclusion'. But another area of ethics relates to the expanding use of such data beyond its original intent (Lyon, 2010), from humanitarian purposes to governmental control of mobility: 'mobile data research has evolved to a point where it can serve international development and migration policy concerns, including the prediction planning or prevention of mobility' (Taylor, 2016, p. 330). Data politics rise again in this context, revealing difficult questions about whose agendas and interests are given priority: states responding to public demands for lower levels of migration, private for-profit corporations which hold and control the data, or researchers from (largely) Western universities bringing highly specialized skills and material resources?

Categories are part of data politics in that they make some people visible and subjects of investigation in the first place: 'numerous kinds of human beings and human acts come into being hand in hand with our invention of the ways to name them' (Hacking, 2004, p. 113). How does this happen? These categories, and the multiple sources of data comprising 
them, are reassembled into 'data doubles' (Haggerty \& Ericson, 2000) that serve as virtual versions of the actual migrant. Then, aggregating these data doubles into populations enables security practitioners and researchers to identify behaviors and individuals with anomalous, risky, or dangerous profiles. Such processes of inference, as they generate various scores or flags for subsequent interpretation, are what Louise Amoore (2011, p. 28) has called 'data derivatives... what can be imagined or inferred about who we might be — on our very proclivities and potentialities'.

In this sense, the implications of using data in settings of human mobility go well beyond the politics of documenting the past or present, as is the case with censuses or surveys. Rather, outcomes include predictions and projections involving future populations that do not yet exist (Amoore, 2009). Once made, these projections become the present reality_objects with weight, inertia, and momentum of their own in public and policy narratives (Anderson, 2017). These processes of generating and acting upon data derivatives are themselves deeply human activities, involving decisions and interpretations that are context-specific to individuals, organizations, societies, and cultures (Allen \& Vollmer, 2017). Measuring mobility implies there is a clear understanding of who migrants are, as well as why (and for whom) their measurement is so important in the first place. This is an instance where mobility politics can inform data politics by contributing a more reflexive understanding of the complexity surrounding human movement and its multiple dimensions.

\section{Messaging mobility: Data visualization and communication}

Besides categorizing, labeling, and creating new kinds of virtual migrant doubles, researchers and practitioners also engage in data politics when they communicate their findings. This aspect of messaging is implied within the GMDAC report quoted in the introduction, when it argues that decision-makers have to be convinced of the value of data for their work. Turning 
attention to the ways that data are assembled to illustrate, convince, and persuade takes migration scholars into the realms of scientific and visual communication. This is because data are rarely presented in their original, tabular forms. Instead, as recently exemplified with various migration datasets (Dennett, 2015) and my own efforts to visualize media representations of migrants (Allen, 2017), data are often communicated visually using charts, maps, and other similar outputs that can be static or interactive (Kirk, 2016). In this section, I focus on key political issues that arise from visually conveying information about mobility. For further discussion about the processes and methodologies used to visualize data, and examples from my own and others' visualization practices, see Kennedy and Allen (2017).

Despite the historical popularity of visually representing scientific ideas (Bucchi \& Saracino, 2016), and widespread guidance preferring relative simplicity in presentation (Frankel, 2002; Tufte, 1983, 2006), the data visualization as a communicative and culturallyspecific artifact should be seen as a complex, multimodal object that is generated by - and generative of - data politics (Hiippala, 2019). As I argue with Helen Kennedy and our colleagues (Kennedy et al., 2016), visualizations and the design conventions within them do ideological work by prioritizing objectivity over other outcomes. For example, we used social semiotics to analyze a specific visualization (Sander, Abel, \& Bauer, 2014) about the flows of migrants among different world regions which uses smooth, colored ribbons to represent migrant populations' movements. Visually, we observe how

[t]his suggests a simple journey, a straightforward transition from one nationstate to another. However, for many migrants the actual process of moving involves transiting through other countries, returns to the country of origin and substantial struggles to gain recognition as migrants...It presents a particular version of human migration because visualisation designers are constrained by conventions, not because they intend to mislead... (Kennedy et al., 2016, p. 729) 
An obvious question that applies to all visualizations of migration relates to whose version of mobility is being represented. A 'god-like' view from above (Kress \& Van Leeuwen, 2006, p. 149), as often contained within maps and diagrams, confers a sense of comprehensiveness and scientific fact. In this setting, migrants might be aggregated into categories that subsequently are associated with specific colors or shapes. On the one hand, this approach is practically useful: it can reveal previously unknown trends and outliers that demand policy or public attention. On the other hand, much like in the case of data derivatives, these aggregations and their representation become objects themselves, and may reproduce assumed norms and hierarchies that benefit more powerful groups. Relatedly, they obscure migrants' plural stories by collapsing similar data doubles into singular variables: employment status, nationality, passport held. These outcomes, intentional or not, matter for debates in policy and practice. Just as creating categories reifies certain identities and statuses, visual representations of these categories do much the same. The migrant becomes part of a mass; migration becomes something to control. Data politics are key to understanding how migration is represented in media as a problem needing the attention of policymakers and the public (Bacchi, 2009).

But data visualizations, just like the data they express, are located within certain contexts, and potentially are the products of several decisions by individuals or institutions (Allen, 2018). These decisions may reflect particular agendas, as Katharina Rall and her colleagues (2016) show in the case of visualizations about human rights, or Rosemary Hill (2017) does in the case of abortion debates. Intermediaries who translate and transmit research findings also can leave their marks on visual outputs as outcomes of certain sets of organizational values like objectivity or comprehensiveness, as I have shown in the case of my own experiences working with migration organizations that liaise with public bodies (Kennedy \& Allen, 2017). Or, changes to visual content may arise out of more practical 
considerations such as topical interest, audience attention, and aesthetic appeal-factors that equally apply to other kinds of research evidence as well as visualizations (Boswell, 2009; Oliver, Innvar, Lorenc, Woodman, \& Thomas, 2014). Therefore, a fuller understanding of data politics in communicating migration through various media requires attending to both the messengers themselves and the circumstances in which they operate.

\section{Developing Frameworks and Methodologies that Connect Data with Mobility Politics}

A new politics of migration and mobility, as suggested by Bridget Anderson (2017, p. 1535), involves 'engaging with the instability of "the migrant"'. I've argued that such engagement takes migration studies into the realm of data politics through a critical understanding of how migrants are enacted and represented in data collected across media, as well as their subsequent visualization (Crawford et al., 2014; Ruppert et al., 2017). As new technologies emerge and are implemented in migration settings — sometimes for banal measurement by statisticians, but other times for more powerful surveillance purposes by governments and private companies (Lyon, 2014) — researchers have a responsibility to open these black boxes where possible and show how their constituent parts and outcomes have political and social consequences (Dalton et al., 2016). Moreover, scholars of media and mobility need to attend to how and for whose benefit these datafied technologies and processes themselves create new kinds of politics — new arrangements of living, working, relating, and being in the world — that simultaneously open up new possibilities while foreclosing others.

I began by questioning the value of statements about whether Big Data approaches in migration policymaking were summarily good or bad. Instead, I sought to open up a more realistic, yet critical, debate predicated on questions including how, for whom, and under what circumstances do data achieve certain purposes. By drawing together a selection of studies, some from my own research practice, I aimed to show how new migration politics 
intersect with data politics in two ways: in the processes of measuring and categorizing migrants and migration; and in representing and communicating these data to decisionmakers and the public.

These kinds of questions potentially offer greater guidance for researchers, policymakers, and practitioners as they engage with an ever-developing nexus between data, media, and mobility. An appreciation of data politics in migration studies brings certain topics to the fore. How do data worlds - both the physical objects and virtual processes enacted by data — create and obscure figures of migrants and citizens? Who benefits and loses from any particular version of mobility? How do these processes arise through the power, values, and assumptions built into them? Can people — whether as individuals or collective groups - change, impact, subvert, or resist these enactments, and if so, how (Bakir, Feilzer, \& McStay, 2017)?

Data politics also have implications for the ways that researchers do their work, especially (but not exclusively) when studying media. The 'subjects' and 'rights' components of data politics should draw scholars' attention to the specific ways that people perceive, use, and engage with media that increasingly involve data worlds. For example, research designs that link analysis of outputs' forms with their effects and creation could productively trace the lifecycle of media messages about mobility, and in turn demonstrate why these messages matter for wider society and politics. This approach would apply not only to studies involving members of the general public who consume media content, but also to producers of that content who are based in newsrooms and journalistic settings (Engebretsen, Kennedy, \& Weber, 2018).

For policy and practice, more pressing concerns relate to navigating the substantial promises and pitfalls associated with new and different forms of data. Coordination and standardization across surveys and censuses offer the possibility of greater coverage of key 
variables, while capitalizing on the relatively well-established and highly-regarded natures of national statistical bureaus (Struijs, Braaksma, \& Daas, 2014). But these tools, their implementation, and their basic assumptions need to be critically examined. What dimensions of mobility might be overlooked or overstated in any single approach or methodology? Are there differences in assumptions and terminologies that vary across contexts, whether considered in temporal, geographic, or linguistic terms - and how would these differences impact the conclusions that emerge from the resulting data? To what extent can an analytical method handle both uncertainty and multiplicity, phenomena that characterize mobility?

Questions about the role of data in media, society, and politics extend well beyond the outcomes of the two Global Compacts. They touch upon fundamental issues about rights, inequalities, and democratic accountability (Andrejevic, 2014; Crawford et al., 2014). Who, for example, has the ability — the privilege — to access, use, or speak with data? How are the uses of data the products of political, social, historical, and cultural contexts and values, and to what extent do they reinforce existing hierarchies of power? Addressing these kinds of issues will require 'a continuous reflection of how and why mobility is made an object of discourse and policy, and what kind of knowledge is produced as migration is rationalized, analyzed and classified' (Anderson, 2017, p. 1535). In practical terms, raising data subjects' skills and awareness in relation to their own data and how it is used-which will likely require developing new kinds of literacies along the way (Gray, Bounegru, Milan, \& Ciuccarelli, 2016)—would be an important step towards doing so.

This chapter outlined what data politics are and how they generate different kinds of questions about the role of data in society. Then it illustrated the relevance of these questions for migration studies through several examples from critical data studies and science and technology studies that focus on the ways that mobility is measured and messaged. A limitation of that brief overview was its focus on European experiences and cases, though the 
lessons for data politics are certainly applicable in developed and developing contexts even if they may likely take different forms. Media and communication scholars, particularly those like myself who work in North American and European settings, need to be mindful of how our chosen objects and processes of research might reinforce what Arjun Appadurai (2016) observed as widening — and worrying — divides among global colleagues. Finally, in an exploratory fashion, it considered what an agenda examining data politics in migration studies might look like for researchers, policymakers, and practitioners. Such an agenda, if it is to produce meaningful and ethical outcomes, should engage with the variety of assumptions and meanings on which assertions about the 'effectiveness' of data-based solutions rely, as well as reflect on its own objects and methods of study. 


\section{References}

Allen, W. (2017). Making corpus data visible: Visualising text with research intermediaries. Corpora, 12(3), 459-482. https://doi.org/10.3366/cor.2017.0128

Allen, W. (2018). Visual brokerage: Communicating data and research through visualisation. Public Understanding of Science. https://doi.org/10.1177/0963662518756853

Allen, W., Anderson, B., Van Hear, N., Sumption, M., Rose, L., Hough, J., ... Walker, S. (2018). Who counts in crises? The new geopolitics of international migration and refugee governance. Geopolitics, 23(1), 217-243. https://doi.org/10.1080/14650045.2017.1327740

Allen, W., \& Vollmer, B. A. (2017). Clean skins: Making the e-Border security assemblage. Environment and Planning D: Society and Space. https://doi.org/10.1177/0263775817722565

Amoore, L. (2009). Lines of sight: On the visualization of unknown futures. Citizenship Studies, 13(1), 17-30.

Amoore, L. (2011). Data derivatives: On the emergence of a security risk calculus for our times. Theory, Culture \& Society, 28(6), 24-43.

Anderson, B. (2017). Towards a new politics of migration? Ethnic and Racial Studies, 40(9), 1527-1537. https://doi.org/10.1080/01419870.2017.1300297

Anderson, B., \& Blinder, S. (2017). Who counts as a migrant? Definitions and their consequences (Migration Observatory Briefing). Oxford: COMPAS, University of Oxford. Retrieved from http://www.migrationobservatory.ox.ac.uk/wpcontent/uploads/2016/04/Briefing-Who_Counts_Migrant.pdf

Andrejevic, M. (2014). The big data divide. International Journal of Communication, 8 , $1673-1689$. 
Appadurai, A. (2016). The academic digital divide and uneven global development. Center for Advanced Research in Global Communication (CARGC). Retrieved from https://repository.upenn.edu/cargc_papers/4

Bacchi, C. (2009). Analysing policy: What is the problem represented to be? Oxford: Pearson.

Bakir, V., Feilzer, M., \& McStay, A. (2017). Introduction to special theme veillance and transparency: A critical examination of mutual watching in the post-Snowden, big data era. Big Data \& Society, 4(1), 2053951717698996. https://doi.org/10.1177/2053951717698996

Ball, S. J. (2015). Education, governance and the tyranny of numbers. Journal of Education Policy, 30(3), 299-301. https://doi.org/10.1080/02680939.2015.1013271

Bengtsson, L., Lu, X., Thorson, A., Garfield, R., \& Von Schreeb, J. (2011). Improved response to disasters and outbreaks by tracking population movements with mobile phone network data: A post-earthquake geospatial study in Haiti. PLoS Medicine, 8(8), 1-9. https://doi.org/10.1371/journal.pmed.1001083

Blumenstock, J. E. (2012). Inferring patterns of internal migration from mobile phone call records: Evidence from Rwanda. Information Technology for Development, 18(2), 107-125. https://doi.org/10.1080/02681102.2011.643209

Boswell, C. (2009). The political uses of expert knowledge: Immigration policy and social research. Cambridge: Cambridge University Press.

Boswell, C., Yearley, S., Fleming, C., Rodrigues, E., \& Spinardi, G. (2015). The effects of targets and indicators on policy formulation: Narrowing down, crowding out and locking in. In A. Jordan \& J. Turnpenny (Eds.), The Tools of Policy Formulation: Actors, Capacities, Venues and Effects (pp. 225-244). Cheltenham: Edward Elgar Publishing. 
boyd, d., \& Crawford, K. (2012). Critical questions for big data. Information, Communication \& Society, 15(5), 662-679. https://doi.org/10.1080/1369118X.2012.678878

Bucchi, M., \& Saracino, B. (2016). 'Visual science literacy': Images and public understanding of science in the digital age. Science Communication, 38(6), 812-819. https://doi.org/10.1177/1075547016677833

Crawford, K., Miltner, K., \& Gray, M. L. (2014). Critiquing big data: Politics, ethics, epistemology. International Journal of Communication, 8, 1663-1672.

Crisp, J. (2018). Beware the notion that better data lead to better outcomes for refugees and migrants. London: Chatham House. Retrieved from https://www.chathamhouse.org/expert/comment/beware-notion-better-data-leadbetter-outcomes-refugees-and-migrants\#

Dalton, C. M., Taylor, L., \& Thatcher, J. (2016). Critical data studies: A dialog on data and space. SSRN. Retrieved from https://ssrn.com/abstract=2761166

Data for Refugees Turkey. (2018). Objectives. Retrieved 14 March 2018, from http://d4r.turktelekom.com.tr/presentation/objectives

Dekker, R., Engbersen, G., Klaver, J., \& Vonk, H. (2018). Smart refugees: How Syrian asylum migrants use social media information in migration decision-making. Social Media + Society, 4(1), 2056305118764439. https://doi.org/10.1177/2056305118764439

Dennett, A. (2015). Visualising migration: Online tools for taking us beyond the static map. Migration Studies, 3(1), 143-152. https://doi.org/10.1093/migration/mnu073

Eberstadt, N. (1995). The tyranny of numbers: Mismeasurement and misrule. Washington, D.C.: The American Enterprise Institute Press. 
Engebretsen, M., Kennedy, H., \& Weber, W. (2018). Data visualization in Scandinavian newsrooms: Emerging trends in journalistic visualization practices. Nordicom Review. https://doi.org/10.2478/nor-2018-0007

Frankel, F. (2002). Envisioning science: The design and craft of the science image. Cambridge, MA: MIT Press.

Gitelman, Lisa, \& Jackson, V. (2013). Introduction. In L. Gitelman (Ed.), Raw Data is an Oxymoron. Cambridge, MA: MIT Press.

Global Migration Data Analysis Centre. (2018). More than numbers: How migration data can deliver real-life benefits for migrants and governments. IOM. Retrieved from https://publications.iom.int/es/system/files/pdf/more_than_numbers.pdf

Gray, J., Bounegru, L., Milan, S., \& Ciuccarelli, P. (2016). Ways of seeing data: Toward a critical literacy for data visualizations as research objects and research devices. In S. Kubitschko \& A. Kaun (Eds.), Innovative Methods in Media and Communication Research (pp. 227-251). Cham: Springer International Publishing. https://doi.org/10.1007/978-3-319-40700-5_12

Hacking, I. (2004). Making up Ppople. In Historical Ontology (pp. 99-114). Cambridge, MA: Harvard University Press.

Haggerty, K. D., \& Ericson, R. V. (2000). The surveillant assemblage. The British Journal of Sociology, 51(4), 605-622. https://doi.org/10.1080/00071310020015280

Hiippala, T. (2019). A multimodal perspective on data visualization. In H. Kennedy \& M. Engebretsen (Eds.), Data Visualization in Society. Amsterdam: Amsterdam University Press.

Hill, R. L. (2017). The political potential of numbers: Data visualisation in the abortion debate. Women, Gender and Research, (1). Retrieved from http://eprints.whiterose.ac.uk/118537/ 
Hood, C. C., \& Margetts, H. Z. (2007). The tools of government in the digital age. Basingstoke and New York, N.Y.: Palgrave Macmillan.

Iliadis, A., \& Russo, F. (2016). Critical data studies: An introduction. Big Data \& Society, 3(2), 2053951716674238.

International Organization for Migration. (n.d.). International migration statistics (Global compact thematic paper). Geneva: IOM. Retrieved from https://www.iom.int/sites/default/files/our_work/ODG/GCM/IOMThematicPaperInternationalMigrationStatistics.pdf

Kennedy, H., \& Allen, W. (2017). Data visualisation as an emerging tool for online research. In N. G. Fielding, R. M. Lee, \& G. Blank (Eds.), The SAGE Handbook of Online Research Methods (2nd Edition). London: SAGE Publications Ltd.

Kennedy, H., Hill, R. L., Aiello, G., \& Allen, W. (2016). The work that visualisation conventions do. Information, Communication \& Society, 19(6), 715-735. https://doi.org/10.1080/1369118X.2016.1153126

Kirk, A. (2016). Data visualisation: A handbook for data driven design. London: SAGE.

Kress, G. R., \& Van Leeuwen, T. (2006). Reading images: The grammar of visual design (2nd ed.). London: Routledge.

Laczko, F., \& Rango, M. (2014). Can big data help us achieve a ‘migration data revolution’? Migration Policy Practice, 4(2), 20-29.

Latonero, M., \& Kift, P. (2018). On digital passages and borders: Refugees and the new infrastructure for movement and control. Social Media + Society, 4(1), 2056305118764432. https://doi.org/10.1177/2056305118764432

Leurs, K., \& Shepherd, T. (2017). Datafication and discrimination. In M. T. Shäfer \& K. van Es (Eds.), The datafied society: studying culture through data (pp. 211-231). Amsterdam: Amsterdam University Press. 
Lyon, D. (2010). Surveillance, power and everyday life. In P. Kalantzis-Cope \& K. GherabMartín (Eds.), Emerging Digital Spaces in Contemporary Society: Properties of Technology (pp. 107-120). London: Palgrave Macmillan UK. https://doi.org/10.1057/9780230299047_18

Lyon, D. (2014). Surveillance, Snowden, and big data: Capacities, consequences, critique. Big Data \& Society, 1(2). Retrieved from http://bds.sagepub.com/spbds/1/2/2053951714541861.full.pdf

Mayer-Schönberger, V., \& Cukier, K. (2013). Big data: A revolution that will transform how we live, work, and think. Houghton Mifflin Harcourt.

Oliver, K., Innvar, S., Lorenc, T., Woodman, J., \& Thomas, J. (2014). A systematic review of barriers to and facilitators of the use of evidence by policymakers. BMC Health Services Research, 14(1), 1-12.

Pawson, R., Greenhalgh, T., Harvey, G., \& Walshe, K. (2005). Realist review: A new method of systematic review designed for complex policy interventions. Journal of Health Services Research \& Policy, 10(suppl 1), 21-34.

https://doi.org/10.1258/1355819054308530

Rall, K., Satterthwaite, M. L., Pandey, A. V., Emerson, J., Boy, J., Nov, O., \& Bertini, E. (2016). Data visualization for human rights advocacy. Journal of Human Rights Practice, 8(2), 171-197.

Rango, M., \& Vespe, M. (2017). Summary report (big data and alternative data sources on migration: From case-studies to policy support). Ispra, Italy: European Commission, Joint Research Centre. Retrieved from https://bluehub.jrc.ec.europa.eu/bigdata4migration/uploads/attachments/cjdelbdgo00h nqazv3u7xi6pd-big-data-workshop-draft-summary-report.pdf 
Ruppert, E. (2007). Producing population (CRESC working paper series). London: The Open University. Retrieved from http://research.gold.ac.uk/7989/1/wp37.pdf

Ruppert, E. (2011). Population objects: Interpassive subjects. Sociology, 45(2), 218-233. https://doi.org/10.1177/0038038510394027

Ruppert, E., Isin, E., \& Bigo, D. (2017). Data politics. Big Data \& Society, 4(2). https://doi.org/10.1177/2053951717717749

Sander, N., Abel, G. J., \& Bauer, R. (2014). The global flow of people. Retrieved 29 September 2017, from http://www.global-migration.info/

Scott, J. C. (1998). Seeing like a state: How certain schemes to improve the human condition have failed. New Haven; London: Yale University Press.

Struijs, P., Braaksma, B., \& Daas, P. J. (2014). Official statistics and big data. Big Data \& Society, 1(1), 2053951714538417. https://doi.org/10.1177/2053951714538417

Taylor, L. (2016). No place to hide? The ethics and analytics of tracking mobility using mobile phone data. Environment and Planning D: Society and Space, 34(2), 319-336.

Tufte, E. R. (1983). The visual display of quantitative information. Cheshire, CT: Graphics Press.

Tufte, E. R. (2006). Beautiful evidence (Vol. 1). Cheshire, CT: Graphics Press.

United Nations General Assembly. (2016). Resolution adopted by the general assembly on 19 September 2016. Retrieved 13 March 2018, from http://www.un.org/en/ga/search/view_doc.asp?symbol=A/RES/71/1 